\title{
CLAD STAINLESS STEELS AND HIGH-NI-ALLOYS FOR WELDED TUBE APPLICATION
}

\author{
Wolfgang Bretz \\ Wickeder Westfalenstahl GmbH \\ Hauptstrasse 6 \\ D-58739 Wickede, Germany
}

Keywords: Cladding, Laser-/TIG Welding, Combined Soldering-Welding Process, Schaeffler Diagram, Hot Cracking and Segregation

\begin{abstract}
Wickeder Westfalenstahl GmbH is cladding stainless steels and Ni-based alloys on different core materials. Strips are used for welded tubes. Final applications are tube heat exchangers and heating elements for example. Investigations have been carried out on clad 304 stainless, Alloy 316 Ti, Alloy 625, Alloy 800, Alloy 840 and Alloy 904L using Laser, Tig and Microplasma welding technique. Wall thicknesses of tubes are between 0.008 " to 0.060 ". Filler metals, when used, are Alloy 309L, Alloy 625, Alloy 82 and Alloy 80/20. Discussion of results includes metallography, hardness, tensile testing, corrosion testing, chemical analysis by EDX, segregation behaviour and crack origin by SEM as well as Schaeffler diagram. Comparisons between different welding processes will be discussed. A new technology of a welding-soldering process, which results in identical root chemical composition is reviewed.
\end{abstract}

\section{Introduction}

Continuous cold roll bonding of dissimilar materials (two or more layers of materials) is a well known pressure-welding process which provides technical and cost advantages in many applications in comparison with a single layer of the expensive material. It allows various material properties to be combined, which a single material cannot achieve. Depending on the requirements, 3 or 5 layers are not rare. Therefore expensive solid materials will only be used when necessary for an application.

The present investigation is focussing on welded tube applications of special SS and Ni-based alloys. These types of material grades are somewhere between SS and Superalloys. Typical alloys of this group are high Ni-based alloys like Alloy $825 \& 625$ for aggressive liquid agents as well as heat resistant alloys like 800,840 and 601 for high temperature applications.

\section{Processes and Discussion}

\section{Cold Roll Bonding Process}

The manufacturing process and production flow of cold roll bonding is shown in Figure 1: The core materials run through different pre-cleaning and activating units. For cladding, surfaces have to be dry, free of oil, grease and other residuals. Even thin oxide layers have to be removed 
mainly by brushing - this means surfaces have to be prepared as virgin materials without any contamination. Roughness characteristics are important. The same requirements are valid for the layer materials. Preparation of layers is done on separate lines.

Before cladding new products the cladding process is simulated by FEM simulations while taking into consideration the speed of rolling, the layer and core materials, tensions introduced by the de- and re-coilers, the degree of reduction and deformation, the angles between layers and the core material in front of the gap, the friction in the gap, which means lubrication as well, the friction between layers and the core, which mainly means roughness of both members.

Furthermore material data like work hardening behaviour of components are important and are taken into account.

After simulation of the cladding process trials are carried out on a lab cladding mill to verify parameters determined by FEM.

Outer layers and inner cores come together in the gap of a 4-high cladding mill and are bonded with a reduction in one step up to $70 \%$ depending on cladding components. After bonding a diffusion bond anneal has to be applied in batch or in continuous horizontal or vertical furnaces. After the diffusion bond annealing the clad strip is finished according to customers' requirements by rolling, annealing, skin passing, slitting and packaging.

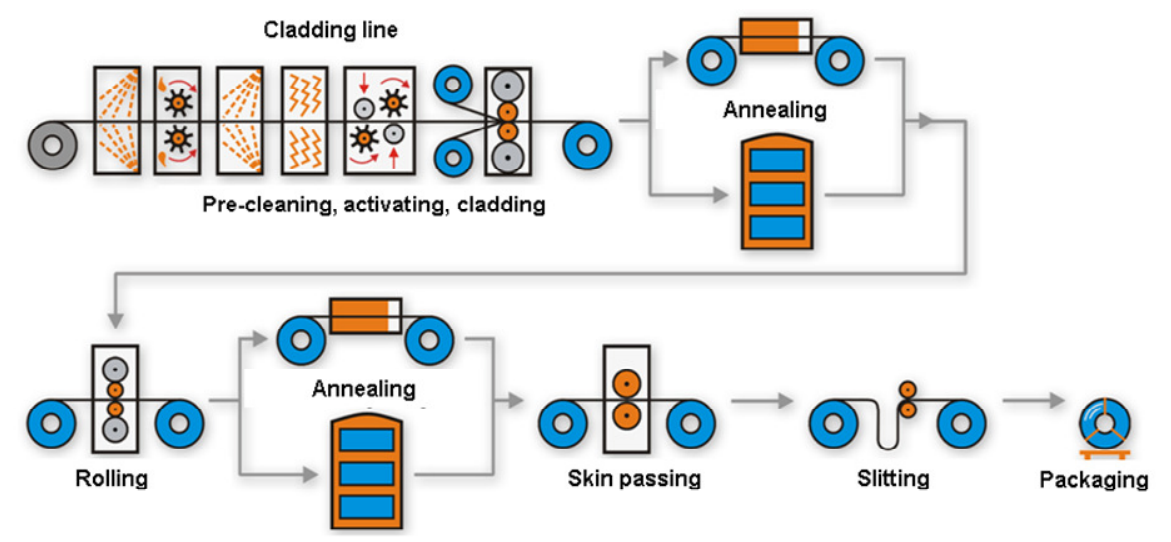

Figure 1. Production Process of Cold Roll Bonding

The bonding produced by the deformation involved in the cold cladding process is significantly improved by the diffusion bonding in the subsequent treatment. When choosing proper heat treatment parameters, the metallurgy of the clad components has to be taken into consideration. This means that phase diagrams have to be studied to determine annealing temperatures and time of exposure at elevated temperatures as well as of the cooling rates to avoid precipitation of harmful phases, which might be brittle or form precipitation and which will lead to a depletion of alloying elements in the matrix causing further undesired phenomena - like precipitation of $\mathrm{Cr}$ carbides in stainless steels which leads to a depletion of $\mathrm{Cr}$ in the matrix. This would lead to a loss of corrosion resistance. 


\section{$\underline{\text { Results of butt welds on clad materials }}$}

Laser butt welds are fundamentals for industrial applications using tube welding lines.

Different filler metals, Alloy 82 and 309L, were tested with laser butt welds on a three layer clad of $304-15 \% 304 / 70 \%$ mild steel /15\% 304 stainless. Total strip thickness was $1.4 \mathrm{~mm}$, while diameter of filler wire was $1.2 \mathrm{~mm}$.

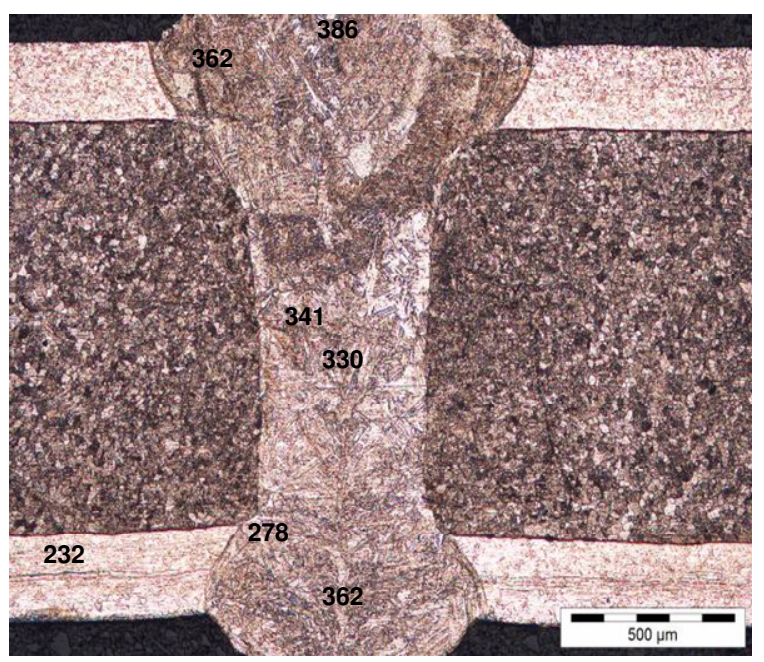

Figure 2. Metallography and Vickers Hardness of Laser welds Alloy 304 clad on mild steel, with filler Alloy 309L

Welds made with filler Alloy 309 L show a martensitic structure (Figure 2,) with hardness values from 350 to nearly $400 \mathrm{HV}$, while using filler Alloy 82 (Figure 3,) welds show an austenitic structure with typical hardness values between 160 to $200 \mathrm{HV}$. Therefore, the need to use fillers with high nickel content is necessary to achieve an austenitic structure as well as corrosion resistance.

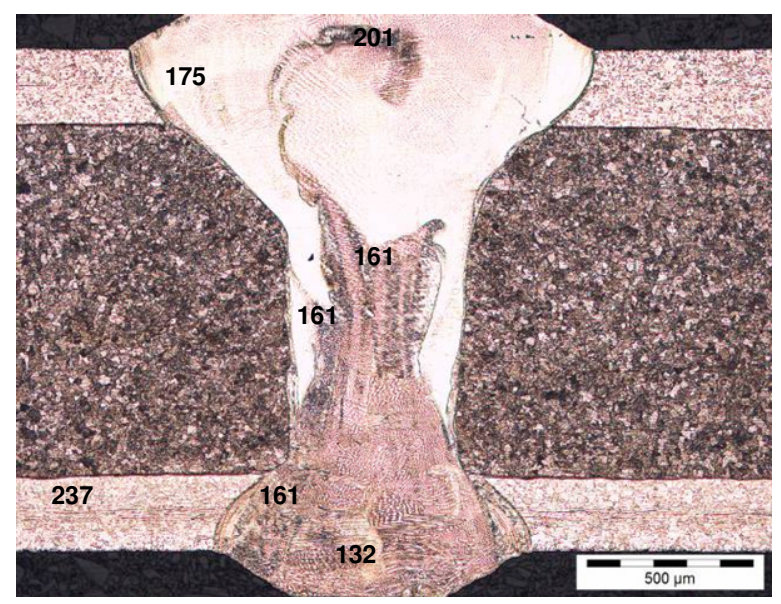

Figure 3. Metallography and Vickers Hardness of Laser welds 304 stainless clad on mild steel, With filler Alloy 82 
Many applications require thicknesses down to $0.2 \mathrm{~mm}$. Therefore wire diameters down to 0.2 mm must be used. The feeder system - (Figure 4,) - , which is used on industrial tube welding lines as well, allows maximum feeder speeds up to $11 \mathrm{~m} / \mathrm{min}$, which is good for line speeds up to $16 \mathrm{~m} / \mathrm{min}$ and therefore fulfils requirements of Laser or TIG tube welding lines.

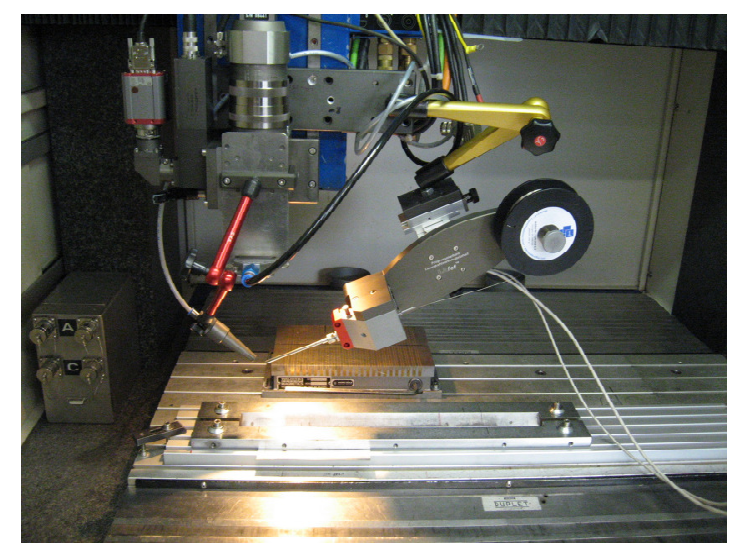

Figure 4. Laser and feeder system

\section{$\underline{\text { Results of tube welds with mild steel and stainless steel cores }}$}

The question, that came up was "How close are the welding results of TIG-welding with Laser welding?" To investigate the different processes, trials were carried out on an industrial tube welding line, which has been equipped with both a TIG-welding gun and with a Laser system. All parameters (line, strip and wire) except for the heating was the same.

Welds were produced using on Alloy $316 \mathrm{Ti}$ clad on mild steel sheets and Alloy 625 as the filler metal. The chemical compositions of the welds were nearly the same. $\mathrm{Ni}$ and $\mathrm{Cr}$ was (as measured by EDX) approximately $16 \%$ and $8 \%$ for the laser welding, and $14 \%$ and $7 \%$ for TIG-welding. Of course the shape of the seam differs - (Figures 5 and 6).

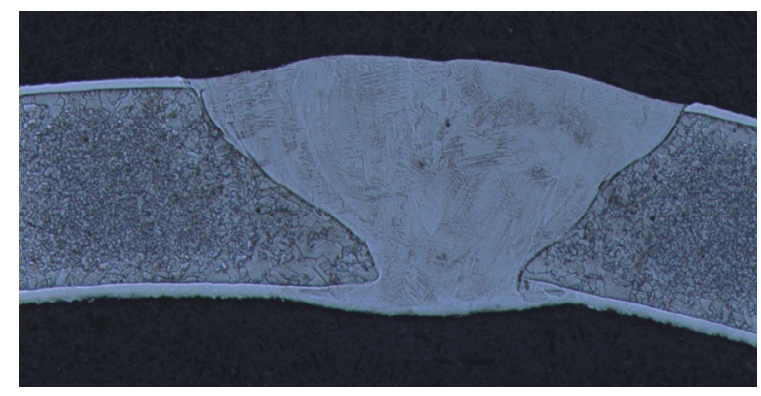

Figure 5. Shape of laser weld, industrial tube welding line 


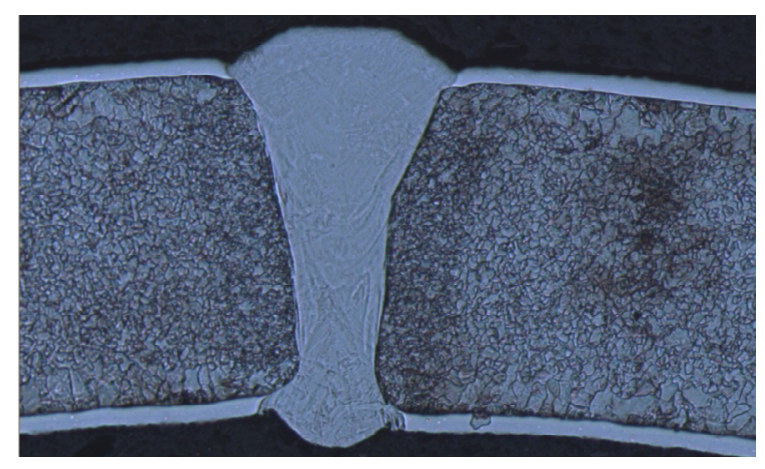

Figure 6. Shape of TIG weld, industrial tube welding line

Beside small differences in chemical composition laser butt welds can be used with good results in continuous tube welding lines.

Unfortunately the corrosion resistance of clad metals with a mild steel core as tested by Salt Spay Test ASTM 117 B is not sufficient even when using high alloyed filler metals like Alloy 625, as the $\mathrm{Cr}$ content dropped below $13 \%$ in the weld bead. Therefore austenitic stainless steels like Alloy 304, 304L or 316 were used as core materials for further investigations and to produce clad material with Alloy 625, 800, 840 and 904L as layer materials.

Austenitic core metals with the afore mentioned layers and filler metals like Alloy 8020,82 and 625 guarantee $\mathrm{Cr}$-contents in the bead of around $18 \%$ and finally an austenitic structure of the seam. Using Alloy 430 as core material might be a cheaper alternative than austenitic stainless steels, but it has to be taken into consideration that austenitic structure has better elongation properties than the ferritic structure.

\section{Combined Soldering-Welding Process}

Austenitic stainless steels can be characterized by lower heat transfer and bigger heat capacity than ferritic steels. Furthermore layers are mostly characterized by high values of alloying elements, which are mostly responsible for lower melting points.

In general this means that the layer material at the root (inside of the tube) melts before the core melts and that more heat will be captured in the layer at the root. Further considering the good gap bridging behaviour of the molten layer material, it should be possible to influence the welding process in a way, so that the weld itself is not breaking through to form the root, but the gap will be closed and covered already by the molten layer. On the other hand this means an identical chemical composition of layer and root, because the root is built up by molten layer in this case. This is important for corrosion requirements on the inside of the tube.

If the seam breaks through, it is not easy to have identical chemical composition at the root compared with the inside layer material. This depends for a degree on the mixture between strip and filler and the circulation of molten pool - mainly.

To investigate this phenomenon a three layer clad, Alloy 800/ mild steel/ alloy 800 in a 10/80/10 ratio, was made using Alloy 82 as the filler metal. Using a filler allows for more heat input into the material without having the welding pool breaking through to the root. That means, that the 
filler metal is used as an additional heating source to put more heat into the material and to avoid breaking through of the molten welding pool.

The result is that the edges of the core material at the lower side are partly molten and the already molten layer - in this case Alloy 800 - will close the gap by capillary forces - Figure 7 .

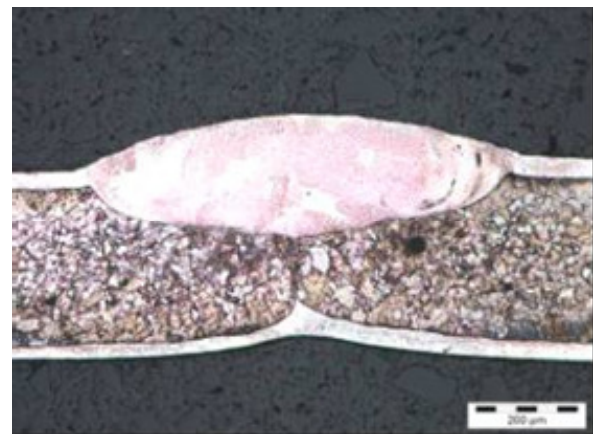

Figure 7. Alloy 800 clad on mild steel, Laser welded with filler Alloy 82

Same results have been achieved on an industrial tube welding line. Alloy 800 was clad on 304 on one side only. Alloy 625 was used as filler metal. EDX-mapping of Ni shows that the process works very well. Different red colours give a hint about the concentration of Ni.- Figure 8.

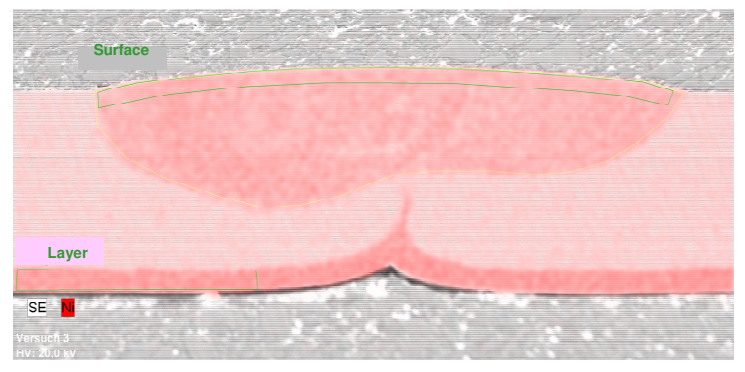

Figure 8. Industrial tube TIG line, Alloy 800 clad on Alloy 304, Filler Alloy 625

Further trials with three layer material Alloy 800/ mild steel/ Alloy 800 of 10/80/10 ratio show the principle, which is behind this process - Figure 9: The layer at the inside of the tube is molten, the gap bridging is closing the gap and melt is creeping into the gap by capillary forces. Furthermore the melt is penetrating and melting the grain boundaries of the core material Figure 9. 


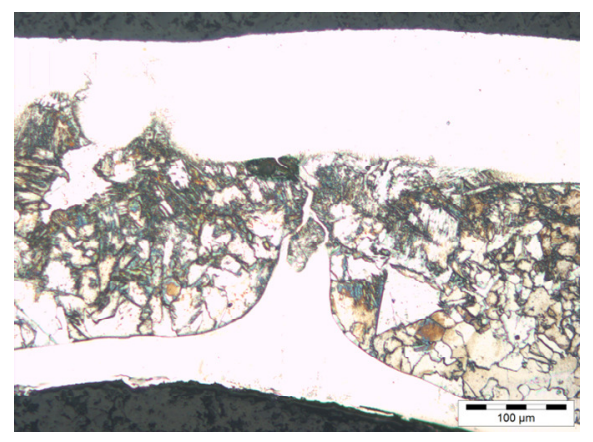

Figure 9. Principle of combined soldering-welding-process

Quantitative EDX-examination of - as it is called - "combined soldering-welding process" gives an overview about the concentration of $\mathrm{Ni}$ and $\mathrm{Cr}$ at the inside of the tube. In this case no filler was used. The welding pool is nearly broken through. It can be easily recognized - Figure 10 that the concentrations of $\mathrm{Ni} \& \mathrm{Cr}$ show right contents for layer and core materials - measuring points M1 \& M6. Next to the pool - measuring points M2 \& M5 - identical chemical composition compared with the layer is found. M4 - very close to the pool - shows a slight decrease of Ni \& Cr, while area scan M3 gives a figure about average composition of weld metal.

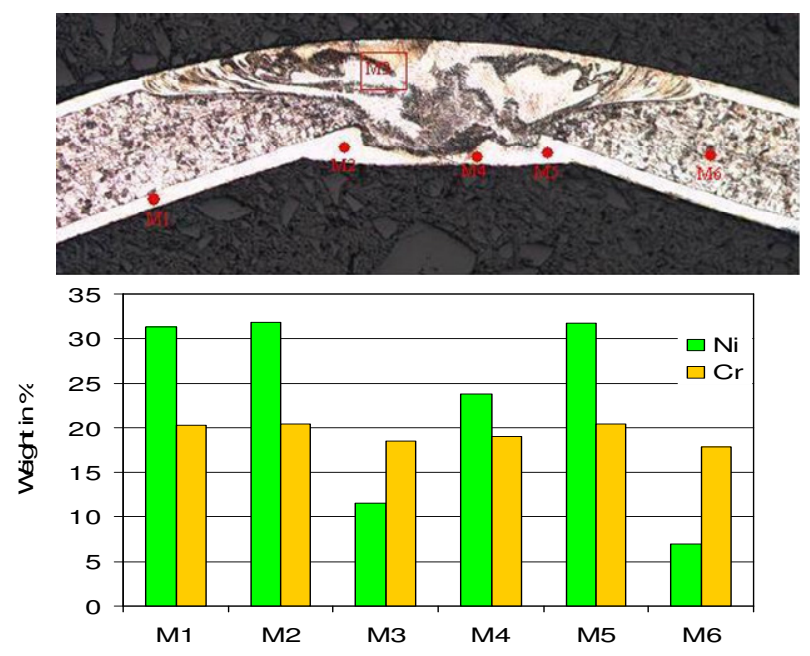

Figure 10. Combined Soldering-Welding-Process in nearly broken through condition

\section{Crack behaviour:}

Using filler 625 sometimes produce heavy dendrite structures in the weld metal - Figure 11 - as well as hot cracks perpendicular to welding direction. From literature it is well known, that Alloy 625 tends towards heavy segregation of Mo and $\mathrm{Nb}$ as well as precipitation of black spots, which have a high content of $\mathrm{Nb}$ up to $20 \%$. Same observations were made at welds produced with filler Alloy 625. 
Hot cracking is in most of the cases a competition between segregation of alloying elements, which are decreasing temperatures of solidification, and shrinkage forces, which are inducing stresses in the weld. At that stage liquid phases or partly solidified material are not yet able to absorb the upcoming stress and therefore hot cracks occur. If there is no or not enough melt left to heal the hot crack, hot cracks are notches, which can be the reason for further progression of the crack. This can be of importance regarding additional cold forming of the tube like bending operations.

Further investigation regarding the character of the hot cracks made clear that there are partly wide areas at the surface showing an as grown structure of free dendrites. Decreasing the weld line speed or increasing the amount of filler metal is not always a solution. On the contrary - hot cracking might become worse.

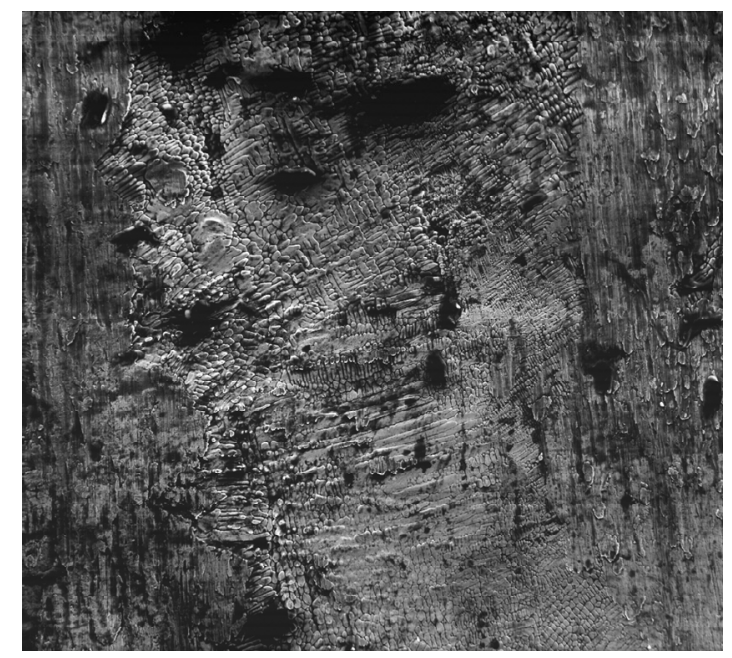

Figure 11. Hot cracking behaviour, industrial tube welding line, clad Alloy 800, filler Alloy 625

Additional hot cracking event (Figure 12) were observed, which resembles eutectic solidification structure. EDX analysis shows that theses sites highly enriched with Ni.

A eutectic system can not be found in relevant phase diagrams, but it is mentioned that these $\mathrm{Ni}$ rich phases reduce solidification temperature down to around $1100{ }^{\circ} \mathrm{C}$.

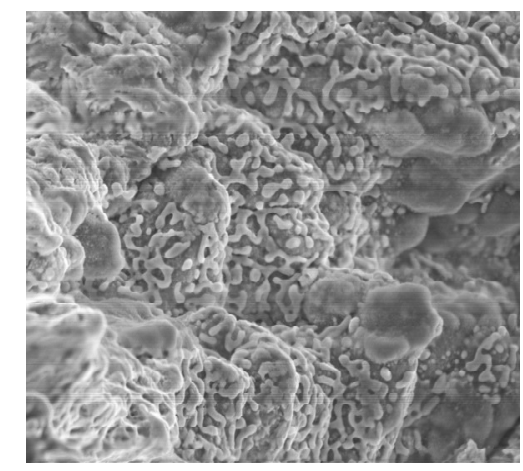

Figure 12. Segregation of Ni-rich phases 
Therefore more attention was paid to the influence of Mo and $\mathrm{Nb}$ regarding hot crack susceptibility. Mo was eliminated first while choosing filler Alloy 82 instead of Alloy 625. Next step was to choose filler Alloy 8020 to get rid of $\mathrm{Nb}$ as well. Results with filler 82 have been pretty good already and are similar to results regarding Alloy 8020 . Finally better resistance against hot cracking can be observed while using Alloy 8020 or 82 instead of Alloy 625.

\section{Influence of different fillers and gaps on chemical composition of weld metal}

Of further interest was the influence of the gap and different filler metals regarding the chemical composition of weld metal, when clad material is used. Therefore butt joints of Alloy 800 clad on alloy $304 \mathrm{~L}$ as core material were Laser welded. The chemical compositions of the different materials are listed in Figure 13.

\begin{tabular}{|l|c|c|c|c|c|c|c|c|c|}
\hline & $\% \mathrm{C}$ & $\% \mathrm{Si}$ & $\% \mathrm{Mn}$ & $\% \mathrm{Cr}$ & $\% \mathrm{Nb}$ & $\% \mathrm{Mo}$ & $\% \mathrm{Ni}$ & \multicolumn{2}{|c|}{ Equivalent } \\
\cline { 5 - 8 } & & & & & & & & $\% \mathrm{Ni}$ & $\% \mathrm{Cr}$ \\
\hline Alloy 304L Core & 0.03 & 1 & 2 & 20 & - & - & 12 & 13,90 & 21,50 \\
Alloy 800 Layer & 0.01 & 0,31 & 0,29 & 19,33 & - & - & 30,35 & 30,80 & 21,75 \\
Filler Alloy 80/20 & 0.025 & 1,36 & 1,20 & 20,44 & - & - & 77,5 & 78,85 & 22,48 \\
Filler Alloy 82 & 0.012 & 0,13 & 3,20 & 20,4 & 2,7 & 0,01 & 73 & 74,96 & 21,95 \\
Filler Alloy 625 & 0.01 & 0,15 & 0,10 & 21,88 & 3,45 & 8,68 & 64,64 & 64,99 & 32,92 \\
\hline
\end{tabular}

Figure 13. Chemical Composition of Core-, Layer-and Filler Materials

Chemical compositions of weld metal were analysed by EDX at the surface of the welds and plotted into a Schaeffler diagram, Figure 14. It is obvious, that changing the gap from zero to 0,1 mm increases content of Ni by nearly $2 \%$. Equivalents of welds made with clad $10 \%$ alloy 800 on 304L and fillers alloys 8020 and 82 show a good correlation with equivalents of solid alloy 800. Filler metal Alloy 625 show a reduced Ni-content of about $7 \%$. 


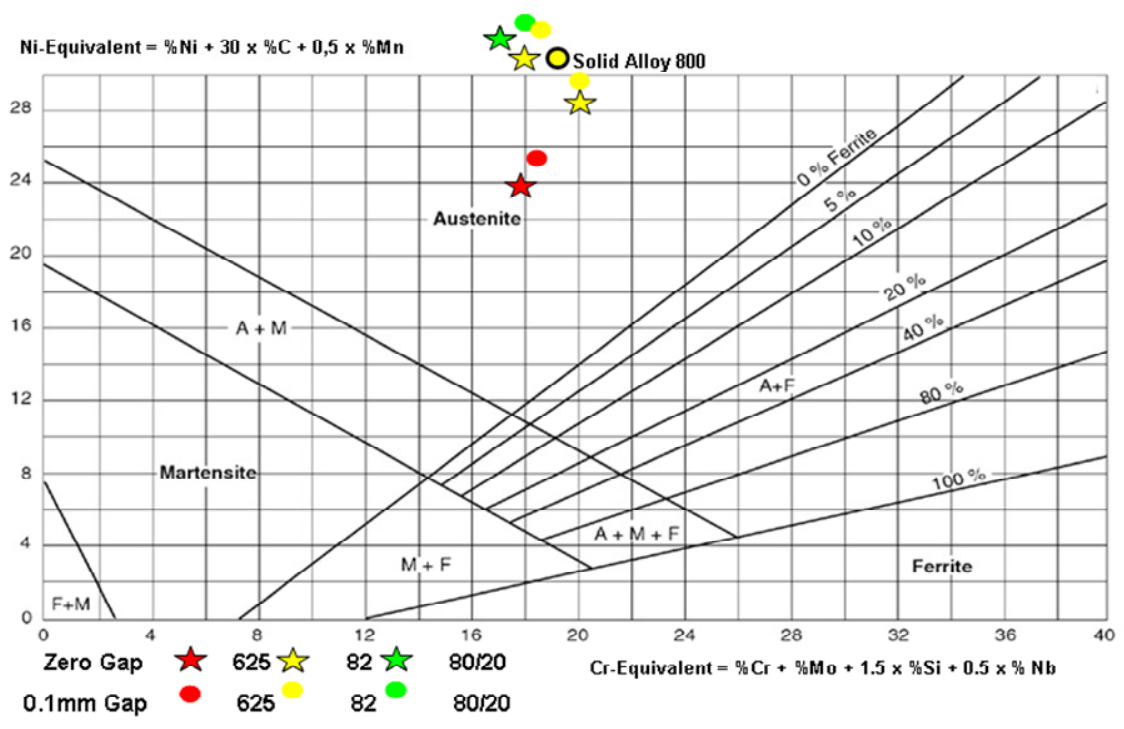

Figure 14. Influence of different Filler Metals and gaps on Ni- and Cr-equivalents Schaeffler Diagram, Clad Alloy 800 on Alloy 304L

\section{Conclusion}

Cold roll bonding of high Ni-based alloys is an alternative to expensive solid alloys for welded tube applications. To weld a seam with TIG- or Laser- technique, which fulfils the requirements of solid alloys, fundamental investigations have been carried out taking the metallurgy of the components into consideration as well as the choice of a proper filler metal. Heavy segregation of Mo and Ni can lead to low melting phases that are responsible for hot cracks. On the other hand is hot cracking a competition between segregation and shrinking stress.

Furthermore a new technique has been experienced, which allows joining of tubes, which have the same chemical composition at the seam at the inside of the tube as the layer alloy has. The mechanism is based on different melting points of core and layer materials and driven by capillary forces. The process is called "Combined Soldering -Welding Process" and works without any filler metal and with both - mild and stainless steel cores as well. Tubes have been produced already on industrial tube welding lines.

Further investigation of other high Ni-based alloys clad on different core materials are carried out at the moment mainly for welded tube applications, like automotive, chemical and petrochemical applications. 